\title{
Diagnostic treatment and reporting criteria for gonorrhoea in sexually transmitted disease clinics in England and Wales
}

\section{2: Treatment and reporting criteria}

\author{
M. W. ADLER
}

From the Departments of Venereology and Genitourinary Medicine and Community Medicine, Middlesex Hospital and Medical School, London

SUMMARY The current methods of treatment and reporting are described. The most common form of treatment for gonorrhoea in men and women was a single dose of oral ampicillin, usually $2 \mathrm{~g}$. In proportionately more of the clinics treating women, treatment was given over several days. The wide use of ampicillin represents a marked change in treatment practice during the last decade. Procaine penicillin was the most commonly used parenteral preparation. The two dosages used most often for men were 1.2 and 2.4 megaunits. In women the commonest regimen was 2.4 megaunits and again there was a tendency for treatment to be given over several days. Epidemiological treatment was used widely and in one-third of clinics this occurred without confirmation that the patient was a true contact. Consultants used varying diagnoses on the quarterly returns for patients treated epidemiologically in whom the smears and/or cultures were negative. Most clinics classified these cases as 'other conditions requiring treatment' (D2) but as many as $19 \%$ of clinics designated these cases as being 'true' gonorrhoea. It is suggested that this results in an overestimate of the number of cases of 'real' gonorrhoea treated in England and Wales.

\section{Introduction}

Part 1 of this paper (Adler, 1978) was concerned with the current methods of diagnosis of gonorrhoea used by consultants in England and Wales. This part describes treatment and reporting criteria.

\section{Results}

\section{TREATMENT FOR GONORRHOEA}

Curative treatment with antibiotics

Tables 1 and 2 show the various types of treatment used for men and women diagnosed as suffering from gonorrhoea. For both sexes oral and parenteral preparations were used in equal proportions. Penicillin in one of its various forms was used most often.

\footnotetext{
Address for reprints: M. W. Adler, Medical Research Council, Sexually Transmitted Diseases Project, James Pringle House, 73-75 Charlotte Street, London W1N 8AA

Received for publication 8 September 1977
}

For men the most commonly prescribed drug was ampicillin, being used in $58(34 \%)$ clinics. In nearly all the clinics (54) a single dose ranging from 0.5 to $3.5 \mathrm{~g}$ was given, the commonest dose was $2 \mathrm{~g}$ (26 clinics) followed by $1 \mathrm{~g}$ (19 clinics) (Figure). In 53 of the 54 clinics using a single dose of ampicillin this was combined with $1 \mathrm{~g}$ of probenecid. In four clinics more than one dose was given, ranging from $1 \mathrm{~g}$ a day for three days to $0.5 \mathrm{~g}$ four times a day for six days. Three of these clinics also used probenecid.

Procaine penicillin was the most commonly used parenteral preparation. Of the $36(21 \%)$ clinics for men in which it was used, 30 gave a single dose ranging from 1.2 to $2 \cdot 4$ megaunits. The two dosages most often used were 1.2 megaunits ( 11 clinics) and 2.4 megaunits (11 clinics). Probenecid was used less often by clinics in which procaine penicillin was prescribed than by those using ampicillin; with ampicillin it was $98 \%$ (53 out of 54) but with procaine penicillin $50 \%$ ( 15 out of 30 ). It is also interesting to note that probenecid was used more 

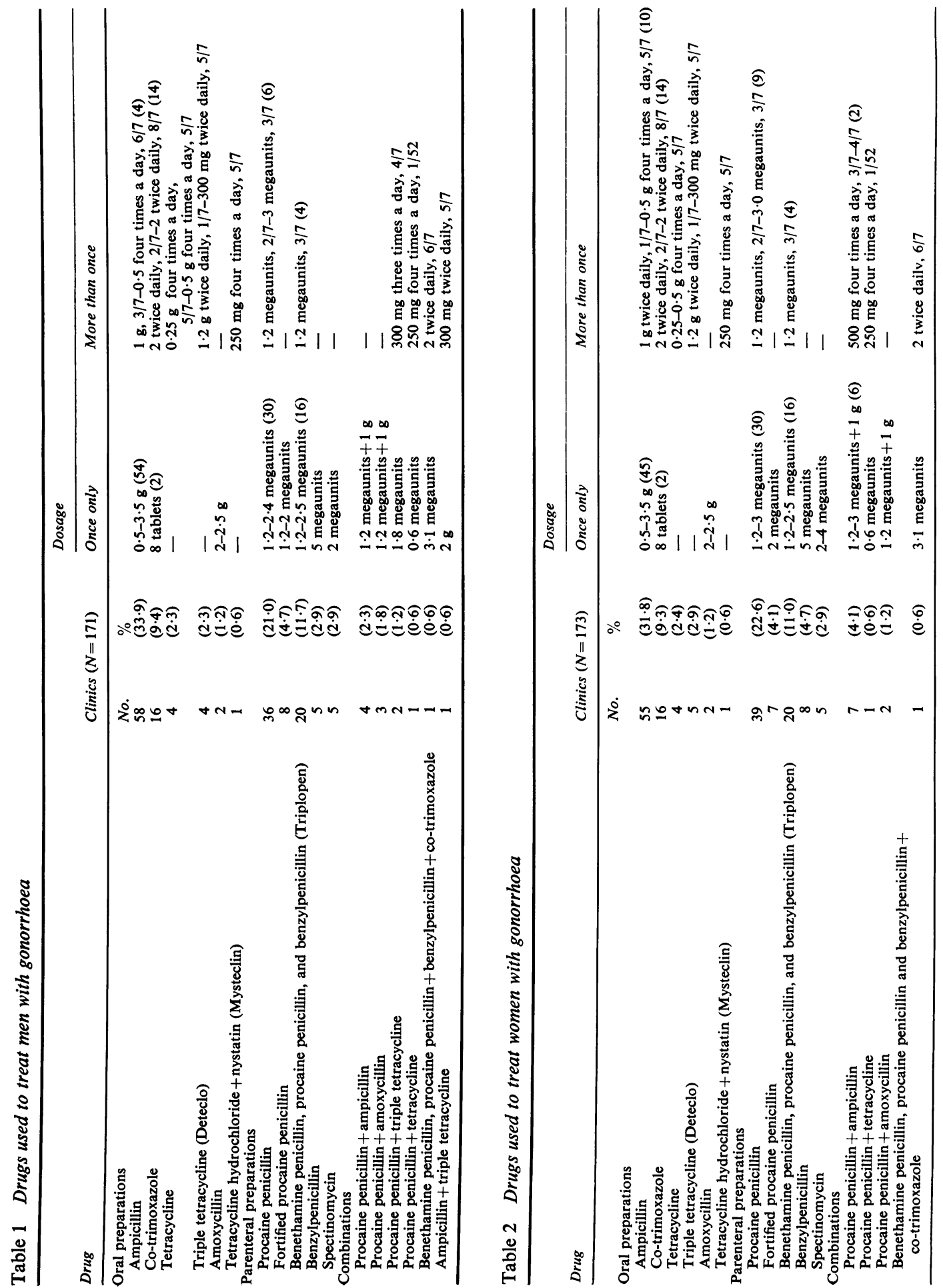

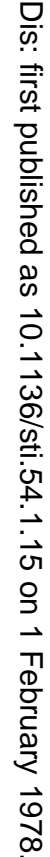

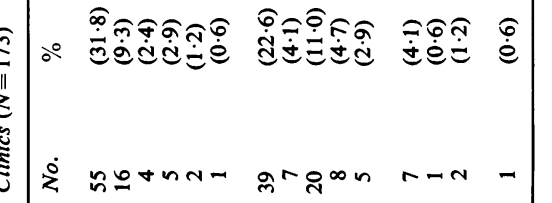

망

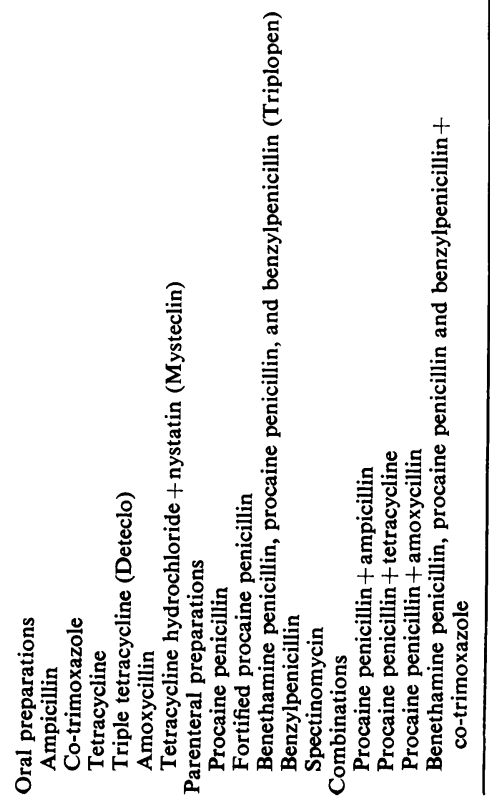



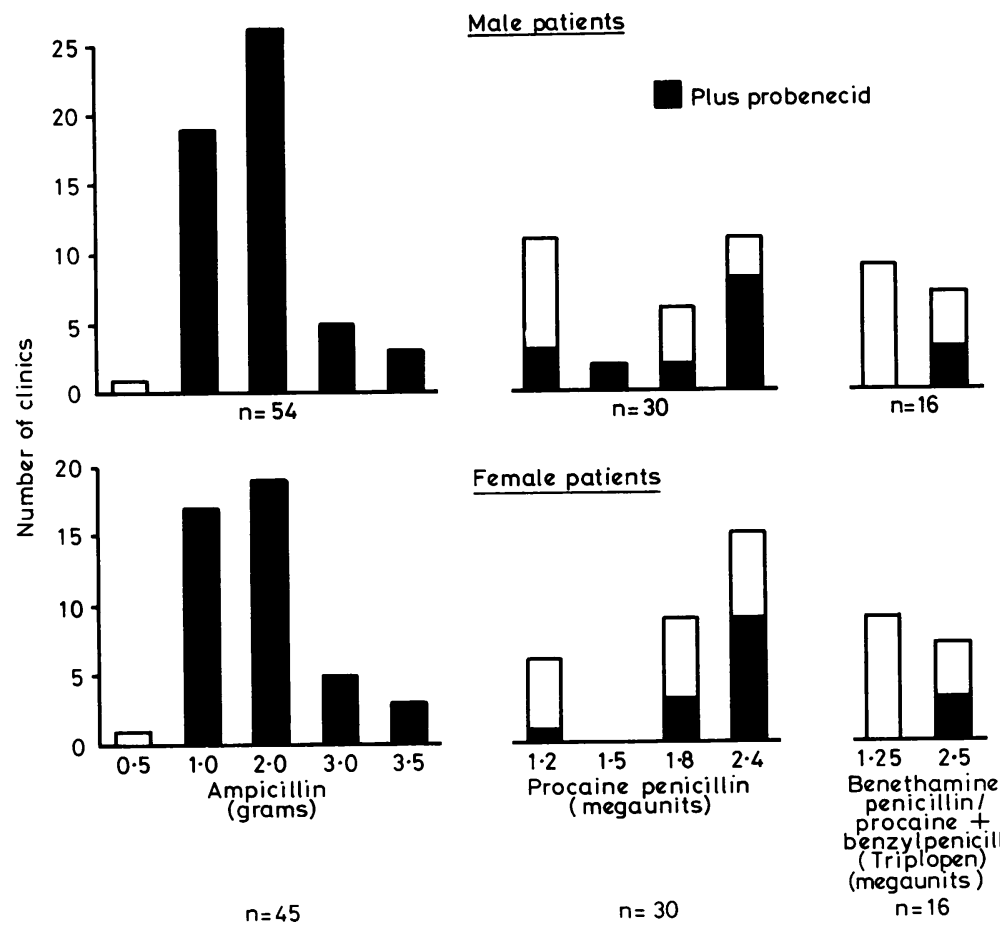

Female patients
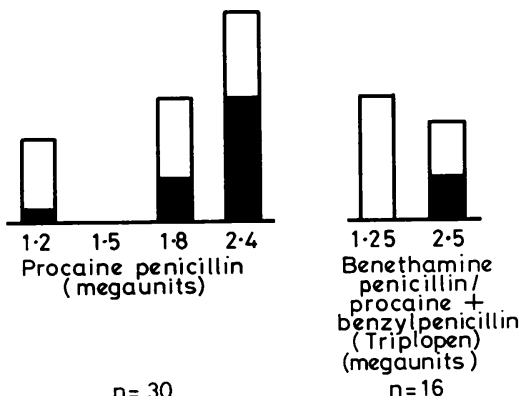

Figure Distribution of dosages for the the three most commonly used drugs in the treatment of gonorrhoea (once only dosages).

often with higher doses of procaine penicillin than with lower. In six clinics procaine penicillin was used more than once, with doses ranging from $1 \cdot 2$ megaunits daily for two days to 3 megaunits daily for three days. Only one of these clinics used probenecid. Benethamine penicillin, procaine penicillin, and benzylpenicillin (Triplopen) was the parenteral preparation next most often used, being prescribed in $20(12 \%)$ clinics for men. It was usually given as a single dose of 1.25 megaunits ( 9 clinics) but it was never combined with probenecid. The higher dosage of 2.5 megaunits was used in seven clinics and at this dosage it was more likely to be combined with probenecid. This trend of giving probenecid with higher doses is similar to that found with procaine penicillin.

The pattern of treatment for women was similar, with ampicillin being the most commonly used treatment followed by procaine penicillin. As with men the single dosage of ampicillin normally used was $2 \mathrm{~g}$ (19 clinics), the next most common was $1 \mathrm{~g}$ (17 clinics). However, in proportionately more of the clinics for women treatment was given over several days-10 $(18 \%)$ out of 55 compared with clinics for men $-4(7 \%)$ out of 58 . The pattern was also true in relation to treatment with procaine penicillin, but to a lesser extent. The single dose of procaine penicillin most often given was 2.4 megaunits (15 clinics) followed by 1.8 megaunits (9 clinics). Again it was commoner to use higher dosages for women than men. The use of probenecid was similar to that in clinics for men in that it was used in all but one clinic prescribing ampicillin as a single dose, and more often with higher doses of benethamine penicillin, procaine penicillin, and benzylpenicillin than with lower ones.

\section{Epidemiological treatment}

In the present study, epidemiological treatment was defined as treatment given to named contacts after a history of exposure but without or in advance of confirmatory pathological findings-namely, treatment in advance of diagnosis. Table 3 shows the proportion of clinics in which this approach was used for different types of patients. Consultants were less inclined to use it for the active homosexual and male heterosexual patients, but more likely to use it for women. Many physicians were prepared 
Table 3 Number of clinics in which consultants were prepared to use epidemiological treatment

\begin{tabular}{lll}
\hline Types of patient & \multicolumn{2}{l}{ Clinics } \\
\cline { 2 - 3 } & No. & $\%$ \\
\hline Women & 148 & $85 \cdot 5$ \\
Homosexuals & 85 & $50 \cdot 0$ \\
$\quad$ Passive & 64 & $37 \cdot 6$ \\
$\quad$ Active & 71 & $41 \cdot 5$ \\
Heterosexual men & & \\
\hline
\end{tabular}

to use epidemiological treatment, but in only one-third of clinics was it used in most cases; in the remainder it was used in selected patients. Those clinics in which this approach was used in most instances were open for a mean of 13 hours a week, and those that used it only in selected cases were open for a mean of 15 hours (mean for England and Wales $=14 \frac{1}{2}$ hours). The commonest reason for using epidemiological treatment was uncertainty that the contact would return to the clinic for results of the tests or to have further tests carried out (Table 4). In one-third of clinics one of the specified reasons was given, in one-third two were given, and in the final third three or more.

Table 4 Reasons for the use of epidemiological treatment in selected gonorrhoea contacts

\begin{tabular}{llr}
\hline Reason & \multicolumn{2}{l}{ Clinics $(N=100)$} \\
\cline { 2 - 3 } & No. & $\%$ \\
\hline Fear of patient defaulting & 60 & $60 \cdot 0$ \\
Patient in transit & 56 & $56 \cdot 0$ \\
Pregnancy & 29 & $29 \cdot 0$ \\
Promiscuity/prostitution & 27 & 27.0 \\
Extramarital sexual intercourse & 15 & $15 \cdot 0$ \\
Reinfection/relapse of original patient & 10 & $10 \cdot 0$ \\
Possible damage to stable relationship & 7 & $7 \cdot 0$ \\
Women with possible salpingitis & 4 & $4 \cdot 0$ \\
Women menstruating & 2 & $2 \cdot 0$ \\
Anxious contact & 2 & $2 \cdot 0$ \\
Recent antibiotics & 1 & 1.0 \\
Patient institutionalised & 1 & 1.0 \\
\hline
\end{tabular}

In one-third of all the clinics using epidemiological treatment a verbal history of contact was considered an adequate reason for instituting epidemiological treatment; these clinics did not demand a contact slip or seek confirmation from another clinic. In the remaining two-thirds of clinics criteria were more stringent and either a slip or confirmation was required.

It was assumed that the consultants who used epidemiological treatment would examine patients and give tests before instituting therapy. However, this was not always so and in three clinics the physicians did not see the contact and supplied the patient with an extra course of treatment to give to him or her. This procedure cannot be described as epidemiological treatment but constitutes treatment by proxy.

A further important aspect of epidemiological treatment is that concerned with the definitive diagnosis for the quarterly returns. Naturally if the tests for gonorrhoea are returned as positive, the patient is automatically counted as a case. However, it was also considered of interest to establish the eventual diagnosis used when a patient had been treated epidemiologically but the tests were negative. Table 5 shows the diagnostic categories used by clinics when the smears and/or cultures were negative and the patient had already been treated. The diagnostic category most often used was that of 'other conditions requiring treatment' (D2). However, in $19 \%$ of clinics consultants included these cases in the quarterly returns as if they were proved cases of gonorrhoea.

Table 5 Diagnostic category used for contacts treated epidemiologically in whom smears and/or cultures were negative

\begin{tabular}{lrr}
\hline Diagnostic category & \multicolumn{2}{c}{ Clinics $(N=148)$} \\
\cline { 2 - 3 } & \multicolumn{1}{c}{ No. } & $\%$ \\
\hline Other conditions requiring treatment (D2) & 106 & $71 \cdot 6$ \\
Gonorrhoea (B1) & 28 & $18 \cdot 9$ \\
Other conditions not requiring treatment (D3) & 7 & $4 \cdot 7$ \\
Non-specific genital infection (C4) & 7 & $4 \cdot 7$ \\
No return & 1 & $0 \cdot 6$ \\
Total & 148 & 100 \\
\hline
\end{tabular}

\section{Empirical/clinical treatment}

This is treatment given to symptomatic patients, who are not named contacts, in advance of smears and/or culture confirmation. It was reported in part 1 of this paper that in some clinics, although a microscopy service was available, treatment was instituted on clinical evidence because smear results were not available at the patient's first attendance. In these circumstances the physicians tended to treat symptomatic patients as if they had gonorrhoea, even when they were not gonorrhoea contacts. In seven clinics for men treatment was based on the history and clinical findings. In four clinics the doctors used one form or another of penicillin and in the remaining three either co-trimoxazole or tetracycline was used. In six clinics women were treated according to the history and clinical findings, in three clinics penicillin was used, and in the other three co-trimoxazole or tetracycline was prescribed.

\section{Prophylactic treatment}

For the purpose of the study prophylactic treatment was defined as treatment given to a symptomless 
patient before or after exposure but without knowledge of the state of health of the consort. This was used in selected cases in $29(17 \%)$ clinics for men, and in $22(13 \%)$ clinics for women (Table 6). No consultant using this technique counted these as cases of gonorrhoea, but most classified them as 'other conditions requiring treatment'. In $93 \%$ of clinics for men and in $77 \%$ of clinics for women using this approach penicillin was prescribed in the form of ampicillin, procaine penicillin, or benethamine penicillin, procaine penicillin, and benzylpenicillin (Triplopen).

Table 6 Reasons for the use of prophylactic treatment

\begin{tabular}{|c|c|c|c|c|}
\hline \multirow[t]{2}{*}{ Reason } & \multicolumn{2}{|c|}{$\begin{array}{l}\text { Clinics for men } \\
(N=29)\end{array}$} & \multicolumn{2}{|c|}{$\begin{array}{l}\text { Clinics for women } \\
(N=22)\end{array}$} \\
\hline & No. & $\%$ & No. & $\%$ \\
\hline \multicolumn{4}{|l|}{ Extramarital sexual } & $45 \cdot 5$ \\
\hline \multicolumn{5}{|l|}{ Going or returning from } \\
\hline abroad & 3 & $10 \cdot 3$ & 4 & $18 \cdot 2$ \\
\hline Patient insists & 3 & $10 \cdot 3$ & 0 & 0.0 \\
\hline Medical colleagues & 1 & $3 \cdot 5$ & 0 & 0.0 \\
\hline Irresponsible/low IQ & 0 & 0.0 & 5 & $22 \cdot 7$ \\
\hline \multirow[t]{2}{*}{ Other } & 0 & 0.0 & 3 & $13 \cdot 6$ \\
\hline & 29 & 100 & 22 & 100 \\
\hline
\end{tabular}

\section{ALCOHOL}

Most consultants asked patients to refrain from taking alcohol during treatment for gonorrhoea. This procedure was adopted in $152(89 \%)$ clinics for men and in $132(76 \%)$ clinics for women. The stated reasons for doing so varied (Table 7). The commonest reason was that alcohol irritates the urethra and increases the severity of the symptoms. This is quite different from having a relapse or a post-gonococcal urethritis which was another commonly cited reason. The second commonest reason was that physicians felt abstention from alcohol would lessen the chances of sexual intercourse resulting from the patient's intoxication. Some doctors admitted that they advocated cessation of alcohol since it was standard and historical practice but were not sure that it was of any use. In two-thirds of clinics one of the reasons was specified and in the remaining third, two of them.

Table 7 Reasons for refraining from alcohol during treatment for gonorrhoea

\begin{tabular}{llc}
\hline Reason & \multicolumn{2}{l}{ Clinics $(N=156)$} \\
\cline { 2 - 3 } & No. & $\%$ \\
\hline Irritates the urethra & 75 & $48 \cdot 1$ \\
Patients should remain sober & 44 & $28 \cdot 2$ \\
Relapse/post-gonococcal urethritis & 41 & $26 \cdot 3$ \\
Standard practice & 25 & $16 \cdot 0$ \\
Delays drug absorption & 19 & $12 \cdot 2$ \\
Other & 16 & $10 \cdot 3$ \\
\hline
\end{tabular}

FOLLOW-UP TESTS AFTER TREATMENT

All patients were seen on at least one further occasion for follow-up tests of cure after treatment (Table 8). The only exception to this was one clinic where male heterosexual patients were never seen again. In most clinics patients were seen on three or more occasions for repeat investigations, other than serological tests.

Table 8 Number of further occasions that patients with gonorrhoea seen and tests repeated after treatment

\begin{tabular}{|c|c|c|c|c|c|c|c|c|}
\hline \multirow[t]{2}{*}{ No. of times } & \multicolumn{2}{|c|}{$\begin{array}{l}\text { Hetero- } \\
\text { sexuals }\end{array}$} & \multicolumn{4}{|c|}{$\begin{array}{l}\text { Homosexuals } \\
\text { Active Passive }\end{array}$} & \multicolumn{2}{|c|}{ Women } \\
\hline & No. & $\%$ & No. & $\%$ & No. & $\%$ & No. & $\%$ \\
\hline None & 1 & 0.6 & 0 & 0.0 & 0 & 0.0 & 0 & 0.0 \\
\hline 1 & 17 & 9.9 & 16 & $9 \cdot 3$ & 16 & $9 \cdot 3$ & 12 & 6.9 \\
\hline 2 & 38 & $22 \cdot 2$ & 35 & $20 \cdot 5$ & 29 & 16.9 & 26 & $15 \cdot 0$ \\
\hline 3 & 55 & $32 \cdot 2$ & 72 & $42 \cdot 1$ & 77 & $45 \cdot 1$ & 81 & 46.9 \\
\hline$>3$ & 60 & $35 \cdot 1$ & 48 & $28 \cdot 1$ & 49 & $28 \cdot 7$ & 54 & $31 \cdot 2$ \\
\hline Total & 171 & 100 & 171 & 100 & 171 & 100 & 173 & 100 \\
\hline
\end{tabular}

QUARTERLY RETURNS FOR GONORRHOEA

Information was obtained about the criteria used in making a return for gonorrhoea to the Department of Health and Social Security (DHSS). Consultants were asked to specify the types of cases and tests required for diagnosing a case of gonorrhoea on the quarterly returns (Table 9). Virtually all the physicians who had microscopical and cultural facilities, and used them, would notify a case if either test was positive.

It was reported (page 13) that in 32 clinics for men and in five for women the diagnosis was made from smears in all or selected patients. In 31 of these clinics the positive smear on its own was considered adequate to identify a case of gonorrhoea, this represents $18 \%$ of all clinics in England and Wales. In seven clinics treatment was given in all or selected instances on empirical or clinical grounds.

Table 9 Criteria used in making a return for gonorrhoea to the Department of Health and Social Security

\begin{tabular}{lcr}
\hline Types of cases & \multicolumn{2}{l}{ Clinics $\left(N=175^{*}\right)$} \\
\cline { 2 - 3 } & No. & $\%$ \\
& 173 & $98 \cdot 8$ \\
With positive smears and positive cultures & 170 & $97 \cdot 1$ \\
$\begin{array}{l}\text { With positive smears and negative cultures } \\
\text { With negative smears and positive cultures }\end{array}$ & 172 & $98 \cdot 2$ \\
$\begin{array}{l}\text { With positive smears only (no culture service or } \\
\text { not used) }\end{array}$ & 31 & $17 \cdot 7$ \\
$\begin{array}{l}\text { Treated on clinical evidence (no microscopy or } \\
\text { cultures) }\end{array}$ & 4 & $2 \cdot 3$ \\
Treated epidemiologically & 28 & $16 \cdot 0$ \\
$\begin{array}{l}\text { Treated prophylactically } \\
\text { *2 clinics no culture service available }\end{array}$ & 0 & $0 \cdot 0$ \\
\hline
\end{tabular}


In four of the clinics a return would be made to the DHSS from the clinical diagnosis without supportive tests.

\section{Discussion}

\section{ANTIBIOTICS}

Consultants prescribing treatment for men and women used 17 and 15 respectively different routine treatment schedules for gonorrhoea. Penicillin in one of its various forms was the commonest type of treatment used, the most popular being oral ampicillin followed by parenteral procaine penicillin.

When ampicillin was first produced in 1961 it was found to have qualities that would allow it to be used in the treatment of gonorrhoea and as a possible alternative to the then widely used parenteral preparations of penicillin. Pharmacologically it has been shown to have distinct advantages over previous oral preparations in that it is acid stable, undergoes less protein binding, and gives a high blood concentration greatest within one to three hours (Acred et al., 1963; Kunin, 1966). In addition it is faster and cheaper to administer, less painful to the patient, with little risk of anaphylaxis and sensitisation.

Only two years after the introduction of ampicillin Willcox (1963) was justified in saying that 'oral antibiotic therapy for the treatment of gonorrhoea ... has not so far had the approval of most venereologists'. In 1968 this was confirmed by the study that he carried out for the British Co-operative Clinical Group (1971) into gonorrhoea practices in Great Britain. This study showed that in those clinics prescribing penicillin, procaine penicillin was used particularly often, being given in $57 \%$ of clinics for men and $54 \%$ of clinics for women. No clinic used ampicillin on its own. The present study indicates that, less than a decade after this last survey, there has been a marked change in treatment practices. Ampicillin is now the single most common form of treatment, being used in one-third of clinics.

This change is partly because treatment with ampicillin is more acceptable to patients and easier to administer in busy clinics than parenteral preparations. The other important factor is the efficacy of the treatment and it has taken a number of years to establish this. Studies were carried out initially to clarify the most appropriate dosage of ampicillin in the treatment of gonorrhoea (Alergant, 1963; Willcox, 1964). These studies used single doses of ampicillin but gave conflicting results, Alergant (1963) reporting a low failure rate $(5 \%)$ and Willcox a higher one of $15 \%$. This prompted Willcox (1965) to examine whether the drug needed to be given more than once. He showed that ampicillin given as two doses of $1 \mathrm{~g}$ divided by five hours gave better results than a once only dose of $1 \mathrm{~g}$, a finding confirmed by others (Groth and Hallqvist, 1970). The use of a divided dose raised doubts about patient compliance and prompted other workers to add probenecid to the regimen so that it could be given only once. Gundersen et al. (1969) was the first person to tackle this problem and showed that a combination of $2 \mathrm{~g}$ of ampicillin plus $1 \mathrm{~g}$ of probenecid given once gave a failure rate of only $1.2 \%$. The final step in the acceptance of ampicillin was in studies that showed that $2 \mathrm{~g}$ of ampicillin plus probenecid was as effective as 1.2 megaunits of procaine penicillin plus probenecid (Cobbold et al., 1973; Willcox et al., 1973). Many of these series are not comparable as different follow-up intervals are used after treatment, criteria of treatment failure vary, and information on penicillin sensitivities of the gonococci is not always available.

It is now accepted that if ampicillin is to be used in the treatment of gonorrhoea the most appropriate dosage is a single one of $2 \mathrm{~g}$ combined with probenecid. In the present study this was the most commonly used dosage but many clinics were using the lower dosage of $1 \mathrm{~g}$ of ampicillin.

The next most common form of treatment was procaine penicillin. In clinics treating men doses of 1.2 and 2.4 megaunits were used equally often, whereas in the clinics treating women the higher dosage was more often used. The fact that clinics treating women tended to use higher dosages is probably a reflection of the difficulty in establishing proof of cure and the concern that they may develop complications-particularly salpingitis. This also accounts for the fact that doctors treating women gave both procaine penicillin and ampicillin in more than one dose more often than for men.

Curtis and Wilkinson (1958) reported that the use of long acting penicillin preparations could result in resistant strains of gonococci and asymptomatic carriers. Both of these situations now exist and even though they are not attributable to the use of any particular antibiotic it is surprising that a preparation such as benethamine penicillin, procaine penicillin, and benzylpenicillin (Triplopen) is still being used so widely. After procaine penicillin it was the most common parenteral preparation of penicillin, being used in $12 \%$ of clinics for men and in $11 \%$ of clinics for women.

Probenecid was used extensively with ampicillin but less often with procaine penicillin or benethamine penicillin, procaine penicillin, and benzylpenicillin (Triplopen) especially for the smaller dosages. Cobbold et al. (1970) and Rodin and Seth (1972) have reported substantially lower failure rates after treatment with 1.2 megaunits of procaine peni- 
cillin combined with probenecid than when the same dose is given without probenecid. A dose of $1 \cdot 2$ megaunits of procaine penicillin is a perfectly acceptable level of treatment, but, in view of this work, it should be combined with probenecid much more readily than when using higher dosages when a certain loss of penicillin through renal excretion is less likely to affect the chances of eventual cure.

Co-trimoxazole was the treatment of choice in $9 \%$ of clinics, almost all the consultants prescribing treatment over several days. Even though co-trimoxazole has been shown to be effective in the treatment of gonorrhoea (Csonka and Knight 1967; Arya et al., 1970; Carroll and Nicol, 1970; Rodin and Seth, 1972), there still remains the problem of compliance. Tablets that have to be taken outside the clinic for a number of days are more likely to be thrown away, stopped before the full course is finished, shared with one or more contacts, or used at a later date in an attempt at self-treatment.

Tetracycline or triple tetracycline (Deteclo) was used in eight clinics for men and in nine clinics for women. Although reasonable results have been obtained using tetracycline or triple tetracycline in the treatment of gonorrhoea (Smithhurst, 1970; Willcox, 1971) compliance is still a problem. In addition there are concerns in relation to sensitive strains of gonococci and cross resistance 'Because of the rapidity with which less sensitive strains of gonococci develop, and the increasing numbers showing cross resistance it is probably advisable not to use tetracyclines for gonorrhoea at the present time' (Lancet, 1972).

\section{EPIDEMIOLOGICAL TREATMENT}

Although epidemiological treatment was used widely throughout England and Wales, the study was not designed to collect opinions about the efficacy of this approach. This has been debated without resolution by venereologists for a number of years (Willcox, 1954, 1968, 1973; King, 1954, 1968; Brown, 1973; King and Nicol, 1975). It seems probable that epidemiological treatment will continue to be used by physicians, and this being so, the present survey has highlighted a number of areas for concern. In view of the lack of precision of this form of treatment it is essential that the doctor be certain that the patient is a true contact at risk of infection. Consultants working in as many as one-third of clinics prescribing epidemiological treatment did so on the consort's verbal history alone, without the production of a contact slip and without confirming with the other clinic what the diagnosis or treatment had heen. Patients are often confused or too overwhelmed to remember their diagnosis or treatment and are therefore unlikely to be able to give exact details to their contacts. Ten years ago a history of treatment by injection would have helped the doctor to establish the most likely diagnosis. But, as has been shown, gonorrhoea is now often treated by tablets and capsules which makes it difficult to differentiate the diagnosis from the more common disease of nonspecific genital infection. It is suggested that, before the institution of epidemiological treatment, clinics should be certain of the disease to which the contact has been exposed. This can be achieved only by requiring the production of a contact slip or telephoning the clinic at which the patient was treated.

After epidemiological treatment has been used and the cultures have confirmed the diagnosis, it is perfectly reasonable to count the case as gonorrhoea for the purpose of the quarterly returns. However, if the cultures are negative it is then unjustifiable to classify the patient as having gonorrhoea. In these circumstances most clinics using epidemiological treatment $(72 \%)$ designated their case as 'other conditions requiring treatment' (D2), but as many as $19 \%$ of clinics classified the case as being one of gonorrhoea. This leads to an overestimate of the true number of cases of gonorrhoea treated in England and Wales. The present study did not attempt to calculate the amount of inflation resulting from this practice but further work is being planned to estimate this.

\section{EMPIRICAL/CLINICAL TREATMENT}

In seven clinics for men and in nine for women smears were not available at the first consultation. Consultants in all the clinics for men and in six of the clinics for women said that they would always treat on the history and clinical findings, or in selected instances. In these circumstances most of the consultants treated the patient as if he had gonorrhoea by giving ampicillin or procaine penicillin. Although some discharges in women strongly suggest a diagnosis, macroscopic evidence is not suitable for an accurate diagnosis; this is especially so in men. If the patient is suffering from non-specific urethritis the use of penicillin is unlikely to give a cure. It is suggested that consultants seeing symptomatic patients, who are not gonorrhoea contacts, should wait for the results of smears and/or cultures so that they can select the most appropriate treatment. Understandably the physician faced with a patient complaining of a discharge will wish to offer immediate treatment, but he should realise that he may be choosing an inappropriate treatment which will be of little long-term benefit to the patient. The solution to this problem is for the consultant without immediate microscopy to insist 
that a microscope is essential for making an immediate presumptive diagnosis.

\section{PROPHYLACTIC TREATMENT}

Prophylactic treatment was used in selected cases in 29 clinics for men and in 22 for women. Whereas there are reasonable arguments for using epidemiological treatment in selected cases it is hard to find any for prophylactic therapy. It is impossible for the clinician to guess whether or not a patient will contract or has contracted an STD while abroad or having casual sexual intercourse. More importantly it is impossible to select an appropriate form of treatment if one has no idea what disease or diseases one is supposed to be treating. Clinics favoured a form of penicillin when treating prophylactically. This therapy is really only effective against gonorrhoea, it can mask syphilis or inadequately treat it, and encourage the spread of penicillin-resistant organisms.

\section{FOLLOW-UP TESTS AFTER TREATMENT}

The policy of physicians for female gonorrhoea contacts in whom the initial investigations were negative was described in part 1 of this paper. It was indicated that in $36 \%$ of clinics investigations were repeated three or more times in these patients. It was suggested that they need not be examined more than twice after the original examination (three times altogether). The same applies to followup tests of cure, two sets of microscopical examinations and cultures being adequate. In all clinics at least one set of tests was carried out but in $78 \%$ of clinics seeing women three or more post-treatment tests were performed.

If more tests than necessary are being carried out new patients may be turned away who might otherwise be seen. It is suggested that instead of carrying out more than three sets of diagnostic tests in female contacts and two tests of cure, physicians should consider devoting their time to seeing new patients and taking urethral tests from asymptomatic male gonorrhoea contacts.

\section{Conclusions}

Current practices in England and Wales for the treatment and reporting of gonorrhoea have been described. It is inevitable and acceptable that there are differences in clinical management. However, in certain instances the workload is being increased unnecessarily by tests being repeated both for establishing diagnosis and cure.

The quarterly returns form the basis of statistics on gonorrhoea and are the only routine indicators of the ability of the service to control this disease. Although it is neither desirable nor necessary to have uniform treatment schedules, it is essential that there be a uniform approach to the completion of the quarterly returns. Cases that are treated epidemiologically and are not confirmed should not be included as cases of gonorrhoea. Unless a standard approach is established consultants may continue to use different criteria and the statistics become of limited and dubious value.

This study was supported as part of a project grant from the Medical Research Council. I should like to thank Miss E. Belsey for her statistical help and Dr B. H. O'Connor for assisting me in carrying out a substantial number of interviews. I am most grateful to Dr R. D. Catterall and Professor D. L. Miller for their encouragement and support, and to Dr C. S. Nicol and Dr R. S. Morton for their comments. I am particularly grateful to Dr R. R. Willcox for his generous advice on the design of the study.

\section{References}

Acred, P., Brown, D. M., Hardy, T. L., and Mansford, K. R. L. (1963). A new approach to studying the protein-binding properties of penicillins. Nature (London), 199, 758-759.

Adler, M. W. (1978). Diagnostic treatment and reporting criteria for gonorrhoea in sexually transmitted disease clinics in England and Wales. I. Diagnosis. British Journal of Venereal Diseases, 54, 10-14.

Alergant, C. D. (1963). Treatment of gonorrhoea with penbritin. A report of 200 cases. British Journal of Venereal Diseases, 39, 225-227.

Arya, O. P., Pearson, C. H., Rao, S. K., and Blowers, R. (1970). Treatment of gonorrhoea with trimethoprin-sulphamethoxazole in Uganda. British Journal of Venereal Diseases, 46, 214-216.

British Co-operative Clinical Group (1971). Survey of gonorrhoea practices in Great Britain. British Journal of Venereal Diseases, 47, 17-26.

Brown, W. J. (1973). Epidemiological treatment of venereal disease contacts. British Journal of Venereal Diseases, 49, 139-140.

Carroll, B. R. T., and Nicol, C. S. (1970). Trimethoprim/sulphamethoxazole in the treatment of non-gonococcal urethritis and gonorrhoea. British Journal of Venereal Diseases, 46, 31-33.

Cobbold, R. J. C., Rees, G. D., Parker, R. B., Woodcock, K. R. John, J., Latto, D., Redmond, A., and Willcox, R. R. (1973). Treatment of gonorrhoea with single oral doses of ampicillin plus probenecid. II. Comparison of results in London and Wales. British Journal of Venereal Diseases, 49, 268-270.

Cobbold, R. J. C., Spitzer, R. J., Morrison, G. D., and Willcox, R. R. (1970). One-session treatment of gonorrhoea in males with procaine penicillin plus probenecid. Postgraduate Medical Journal, 46, 142-145.

Csonka, G. W., and Knight, G. J. (1967). Therapeutic trial of trimethoprim as a potentiator of sulphonamides in gonorrhoea. British Journal of Venereal Diseases, 43, 161-165.

Curtis, F. R., and Wilkinson, A. E. (1958). A comparison of the in vitro sensitivity of gonococci to penicillin with the results of treatment. British Journal of Venereal Diseases, 34, 70-82.

Groth, O., and Hallqvist, L. (1970). Oral ampicillin in gonorrhoea. Clinical evaluation. British Journal of Venereal Diseases, 46, 21-26.

Gundersen, T., Ødegaard, K., and Gjessing, H. C. (1969). Treatment of gonorrhoea by one oral dose of ampicillin and probenecid combined. British Journal of Venereal Diseases, 45, 235-237.

King, A. J. (1954). For and against treatment before diagnosis. British Journal of Venereal Diseases, 30, 13-18. 
King, A. (1968). Letter: Treatment of venereal diseases. British Medical Journal, 4, 581.

King, A., and Nicol, C. (1975). Venereal Diseases, third edition. Ballière Tindall: London.

Kunin, C. M. (1966). Clinical pharmacology of the new penicillins. I. The importance of serum protein binding in determining antimicrobial activity and concentration in serum. Clinical Pharmacology and Therapeutics, 7, 166-179.

Lancet (1972). Leading article: Single dose treatment of gonorrhoea. Lancet, 1, 885-886.

Rodin, P., and Seth, A. D. (1972). Treatment of gonorrhoea with cotrimoxazole, procaine penicillin alone, and procaine penicillin plus probenecid. British Journal of Venereal Diseases, 48, 517-521. Smithhurst, B. A. (1970). Treatment of acute gonococcal urethritis with three drug regimes. In 768 males, Brisbane, Queensland, 1967-69. British Journal of Venereal Diseases, 46, 398-400.

Willcox, R. R. (1954). Treatment before diagnosis in venereology. British Journal of Venereal Diseases, 30, 7-12.

Willcox, R. R. (1963). Ampicillin (Penbritin) in the treatment of gonorrhoea. British Journal of Venereal Diseases, 39, 164-167.
Willcox, R. R. (1964). The newer penicillins in the treatment of gonorrhoea. Postgraduate Medical Journal, 40, Supplement, 202-209.

Willcox, R. R. (1965). Ampicillin divided doses in the treatment of gonorrhoea. British Journal of Clinical Practice, 19, 689-691.

Willcox, R. R. (1968). Letter: Treatment of venereal diseases. British Medical Journal, 4, 388.

Willcox, R R (1971). Treatment of gonorrhoea with two oral doses of antibiotics. Trials of cephalexin and of triple tetracycline (Deteclo). British Journal of Venereal Diseases, 47, 31-33.

Willcox, R. R. (1973). 'Epidemiological' treatment in venereal diseases other than syphilis. British Journal of Venereal Diseases, 49, 116-125.

Willcox, R. R., Woodcock, K. R., Latto, D., John, J., Redmond, A., Parker, R. B., Rees, G. D., and Cobbold, R. J. C. (1973). Treatment of gonorrhoea with single oral doses of ampicillin plus probenecid. I. Comparison with procaine penicillin. British Journal of Venereal Diseases, 49, 263-267. 